Danúzia da Silva Rocha ${ }^{1}$

Fabíola Zíoni²

Ana Cássia Andrade Caetano ${ }^{1}$

\title{
ADVOCACIA SANITÁRIA, CIDADANIA E PARTICIPAÇÃO SOCIAL: ANÁLISE, HISTÓRICO E CONQUISTAS DA ASSOCIAÇÃO DOS PORTADORES DE HEPATITE DO ACRE
}

Health advocacy, citizenship, and social activism: analysis, history, and achievements of the Acre Association of Patients with Hepatitis

${ }^{1}$ Universidade Federal do Acre. Rio Branco/AC, Brasil.

${ }^{2}$ Universidade de São Paulo. São Paulo/SP, Brasil.

Correspondência: Danúzia da Silva Rocha. E-mail: danuziarocha@yahoo.com.br.

Recebido em: 07/05/2014. Revisado em: 15/10/2014. Aprovado em: 22/10/2014. 


\section{RESUMO}

Este artigo relata a trajetória desde a fundação, passando pela consolidação até as conquistas da primeira organização não governamental criada por portadores de hepatites no Brasil. Trata-se de um relato de experiência, que objetivou descrever a luta dos portadores de hepatites crônicas do Estado do Acre pelo tratamento de saúde de que necessitavam. O Acre é o estado do Brasil com maior número de casos de portadores de hepatites. Devido a essa magnitude, fez-se necessário o ativismo dos portadores da doença, em busca de melhorias na assistência à saúde e de acesso ao tratamento gratuito. Para o alcance da assistência integral à saúde, conforme preconizado pela legislação, os ativistas valeram-se de vários artifícios, como o apelo ao poder público, a mobilização social, a mídia e ações judiciais. Assim, os portadores, organizados na forma de ONG, se empoderaram e, na busca pela efetivação de direitos constitucionalmente instituídos (mas, na prática, negados), exerceram ações de cidadania e advocacia sanitária.

\section{Palavras-chave}

Advocacia Sanitária; Associação; Hepatite.

\section{ABSTRACT}

This study reports the trajectory of the first nongovernmental organization (NGO) created by patients with hepatitis in Brazil, from its inception to its achievements. The objective of this experience report was to describe the struggle faced by the patients with chronic hepatitis in Acre to obtain the healthcare services they required. Acre is a Brazilian state with the highest number of hepatitis cases. Considering this magnitude, active involvement of patients with hepatitis was necessary to attain improvements in healthcare services and access to free treatment. To gain access to comprehensive healthcare services, as established by law, these patients used various strategies, including government appeals, social mobilization, media, and lawsuits. In doing so, they organized into an NGO, became empowered, and while seeking their rights which were constitutionally established yet denied in practice, exercised activities pertaining to citizenship and health advocacy.

\section{Keywords}

Association; Health Advocacy; Hepatitis. 


\section{Introdução}

As hepatites virais configuram um grave problema de saúde pública de abrangência mundial. Ocorrem em todos os continentes, tendo repercussão na vida de portadores e seus familiares, além de a morbimortalidade afetar aspectos econômicos, culturais e sociais. Cerca de um milhão de pacientes morrem anualmente em função do comprometimento do fígado causado pelo HBV. Além disso, estima-se que de $50 \%$ a $60 \%$ das pessoas que estão aguardando transplante hepático são portadoras de $\mathrm{HBV}$ ou $\mathrm{HCV}^{1}$.

No Brasil, no período compreendido entre 1999 e 2011, foram notificados 120.343 casos de hepatite B e 82.041 de hepatite C, além de 2.197 de hepatite $\mathrm{D}$ - os três tipos causados por vírus que estão relacionados às formas crônicas e mais graves da doença ${ }^{2}$. A Bacia Amazônica é considerada área de alta endemicidade para hepatites: no período compreendido entre os anos de 1999 a 2011, foram registrados no Brasil 2.197 casos de hepatite Delta (D), sendo que 76\% deles encontravam-se na Região Norte. Destaca-se que, nos estados do Acre e do Amazonas, foram confirmados 1.456 casos no período.

O Acre é o estado com a maior taxa de detecção de hepatite B do país, com uma incidência de 56,8 casos por 100 mil habitantes - sendo que a taxa total da Região Norte é de 11 casos por 100 mil habitantes. Observa-se, assim, que a incidência no Acre é cinco vezes maior do que na Região Norte, ficando bem acima do segundo estado com maior taxa (Rondônia, com 29,12 casos por 100 mil habitantes). Considerando-se a taxa nacional, esse número é oito vezes maior, pois a incidência no Brasil é de 6,9 casos por 100 mil habitantes. Com relação à hepatite C, com uma taxa de 18,1 casos por 100 mil habitantes, o Acre continua liderando o ranking no país. No caso da hepatite $\mathrm{D}$, o Acre também tem a maior taxa do Brasil, de 8,96 casos por 100 mil habitantes, sendo que na Região Norte como um todo é de 0,69 casos por 100 mil habitantes e, no país, de 0,07 casos por 100 mil habitantes ${ }^{3}$. Porém, um estudo realizado por Silva et al. ${ }^{4}$ no Centro de Hematologia e Hemoterapia do Acre (Hemoacre) revelou que, entre os doadores de sangue, o índice de reatividade ao antígeno da hepatite B é de 6 casos para cada mil pessoas que doam sangue. Se considerarmos este último dado, essa incidência se eleva para 600 a cada 100 mil habitantes.

${ }^{1}$ SECRETARIA DE ESTADO DE SAÚDE DO ACRE. Assessoria. Agência de Notícias do Acre. Dia de Conscientização da Hepatite B no Acre. Rio Branco, 2007.

2MINISTÉRIO DA SAÚDE. Secretaria de Vigilância em Saúde. Boletim Epidemiológico-Hepatites Virais, ano 3, n. 1, 2012. Disponível em: <http://www.aids.gov.br/sites/default/files/anexos/publicacao/2012/51820/ boletim_epidemiol_gico_hepatites_virais_2012_ve_12026.pdf>. Acesso em: 30 mar. 2014.

${ }^{3}$ Id. Ibid.

${ }^{4}$ SILVA, Rita do Socorro Uchôa et al. Avaliação da pré-triagem sorológica para o marcador do vírus da hepatite $\mathrm{B}$ (anti-HBc total) em candidatos à doação de sangue no Estado do Acre, 2002. Revista da Sociedade Brasileira de Medicina Tropical, v. 39, n. 2, p. 179-182, mar./abr. 2006. 
Conforme registros do Ministério da Saúde, no período de 2000 a 2011 houve 554 óbitos no estado por hepatites virais (incluem-se aí causas básica e associada à doença), o que enfatiza a magnitude do problema. Com relação à forma clínica apresentada, 77,6\% dos casos de hepatite B e 97,9\% dos de hepatite C evoluíram para a forma crônica da doença, evidenciando-se assim a crescente demanda por acompanhamento e tratamento desses $\operatorname{casos}^{5}$.

Desse modo, observa-se que o estado tem um contingente considerável de pessoas que recorrem ao poder público na busca de atenção às necessidades oriundas da doença e suas consequências.

Vale ainda ressaltar que, no Estado do Acre e na capital Rio Branco, caracteriza-se um quadro em que jovens e adultos jovens - faixa etária em que se está em pleno período reprodutivo e produtivo para o trabalho e para o estudo - constituem população significativamente acometida pela doença e suas implicações ${ }^{6}$. Observa-se que, do total de casos confirmados, a menor proporção (16\%) encontra-se na faixa etária de 40 a 49 anos de idade; metade dos casos está concentrada em indivíduos menores de 30 anos 7 .

Este artigo é um relato de experiência, que descreve a conquista dos portadores de hepatite crônica do Estado do Acre ao tratamento da doença de forma integrada e contínua, conforme preconizado pelo Sistema Único de Saúde (SUS) e garantido pela Constituição Federal de 1988 (CF/88). Há a narrativa de toda a trajetória da luta dessas pessoas até a conquista da assistência a suas necessidades. Tal trajetória foi marcada por conflitos com a gestão local do SUS, sendo necessária a intervenção da Justiça, como será descrita a seguir. Houve, nesse caso em particular, o protagonismo dos próprios portadores, que se organizaram em forma de associação e buscaram validar seus direitos por meio de vários caminhos. Assim, pretende-se discutir o papel da organização na luta por direitos e pela consolidação e participação social. As informações foram obtidas em jornais de circulação diária na capital do citado estado e em entrevistas com associados à APHAC (inclusive com seu atual presidente), entre outros. O texto inicia-se com uma breve contextualização. Em seguida, relata a história da associação e sua luta pela validação dos direitos das pessoas acometidas pelos vírus das hepatites. Por fim, retrata os prejuízos socioeconômicos e culturais dos portadores.

\section{0 contexto: o Estado do Acre e a cidade de Rio Branco}

O Estado do Acre está localizado na Região Norte do Brasil e participa da Amazônia Ocidental, fazendo fronteira ao norte e ao leste com os estados

\footnotetext{
${ }^{5}$ MINISTÉRIO DA SAÚDE. Secretaria de Vigilância em Saúde. Boletim Epidemiológico-Hepatites Virais. op.cit. ${ }^{6}$ PÊSSOA, Isabela Nogueira. Aproximações acerca do cotidiano: enigmas e revelações de pessoascom hepatite B. 2009. 140 p. Dissertação (Mestrado) - Faculdade de Saúde Pública, Universidade de São Paulo, São Paulo, 2009.

${ }^{7}$ MINISTÉRIO DA SAÚDE. Secretaria de Vigilância em Saúde. Boletim Epidemiológico-Hepatites Virais. op.cit.
} 
brasileiros do Amazonas e de Rondônia, respectivamente, ao sudeste com a Bolívia, e ao sul e ao oeste com o Peru, compondo uma área geográfica de aproximadamente 152.582.000 quilômetros quadrados, que compreende seus 22 municípios (Figura 1). O Acre tem uma população de 733.559 habitantes, sendo que 50,4\% desse total correspondem ao sexo masculino. Apresenta Índice de Desenvolvimento Humano (IDH) de 0,697. O analfabetismo na população de 15 anos ou mais equivale a $17,59 \%$ - nacionalmente, a taxa é de $10,38 \%$. O PIB per capita do estado é de R $\$ 8.789$, enquanto nacionalmente esse valor é de $\mathrm{R} \$ 11.658,11$. A proporção de pobres está em $51,31 \%$ - essa mesma medida no Brasil é de $33,12 \%$. A taxa de desemprego estadual é de $5,6 \%$, contra a taxa nacional de $8,42 \%^{8}$.

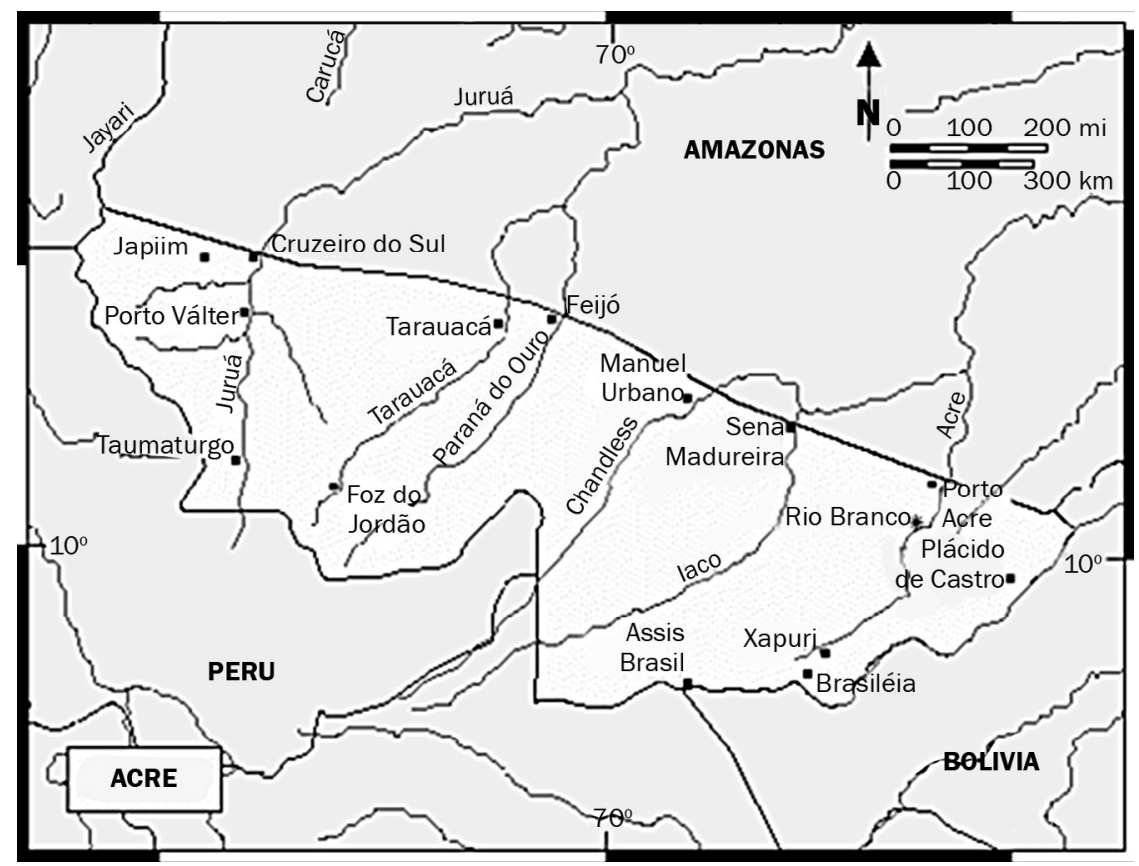

Figura 1. Mapa político do Estado do Acre.

'SECRETARIA DE ESTADO DE PLANEJAMENTO. Acre em números: 2013. Rio Branco: Secretaria de Estado de Planejamento, 2013. Disponivel em: <http://www.ac.gov.br/wps/wcm/connect/e0c7fd0042426ebe9196b371c3a11451/Acre+Em+Nu\%CC\%81meros+2013+web+editado.pdf?>. Acesso em: 30 mar. 2014. 
Conforme o exposto, o contexto socioeconômico do estado é desfavorável em relação ao restante do país. E, por se tratar de região pobre, a situação dos portadores de hepatite fica mais agravada, pois a maioria dos que são acometidos pela doença está nas categorias menos favorecidas. Considerando o alto custo do tratamento e sua quase total inviabilidade de custeio por recursos próprios devido aos dados apresentados, apresentamos a seguir o valor monetário e social do tratamento.

\section{Custos socioeconômicos e culturais do tratamento das hepatites crônicas}

Em relação ao custo financeiro do tratamento, segundo a gerência técnica do Centro de Referência para Medicamentos Especializados (Creme) do estado, o custo mensal apenas com medicações para o portador de hepatite C (de acordo com a terapêutica preconizada pela Portaria n. $34 / 2007^{9}$ ) pode chegar a $\mathrm{R} \$ 4.480,56$; para o tratamento das hepatites B e B mais D, varia de $\mathrm{R} \$ 4.004,99$ a $\mathrm{R} \$ 4.599,36$, dependendo do caso e das drogas escolhidas (e também de acordo com o protocolo do Ministério da Saúde). O tratamento é de no mínimo seis meses, podendo se estender por vários anos. Esses dados explicitam a impossibilidade, para a maioria dos portadores da doença, de custear seu próprio tratamento.

O jornalista Villas-Boas ${ }^{10}$, em seu trabalho de reportagem que retrata as condições de vida dos portadores de hepatite B e D do Acre, estimou que o custo total do tratamento de um paciente com hepatites B ou BD, incluindo medicações, internações, sorologias, exames de biologia molecular, biópsias, endoscopias e medicamentos diversos - pode chegar a aproximadamente $\mathrm{R} \$ 30$ mil por ano. Ele defendeu ainda que, evidentemente, quase ninguém na região amazônica, uma das mais pobres do Brasil, pode arcar essas despesas.

Além do custo altíssimo do tratamento, conforme mencionado, os portadores da doença também sofrem com prejuízos socioeconômicos e até culturais, impostos a quem é acometido por uma hepatite crônica. Essas pessoas passam por mudanças bruscas no que diz respeito às relações sociais, às relações de trabalho e aos hábitos culturais. Tais mudanças ocorrem devido à nova rotina que se estabelece na vida dos portadores devido ao tratamento, a seus efeitos colaterais e às limitações impostas pela própria doença.

Somados as mortes e internações hospitalares, que são prejuízos diretos mais sentidos, essas doenças têm como consequência o absenteísmo no trabalho e na escola, trazendo um grande ônus social e econômico. Dentre os efeitos sentidos

\footnotetext{
${ }^{9}$ MINISTÉRIO DA SAÚDE. Secretária de Vigilância em Saúde. Portaria n. 34, de 28 de setembro de 2007. Dispõe sobre Protocolo Clínico e Diretrizes Terapêuticas para Hepatite Viral C. Disponível em: <http://bvsms.saude.gov.br/bvs/saudelegis/svs/2007/prt0034_28_09_2007.html>. Acesso em: 06 mar. 2015.

${ }^{10}$ VILLAS-BOAS, Sérgio. Murmurs from the silence: a report $\mathrm{n}$ hepatitis B and Delta in the Amazonia State of Acre, Brasil. Barueri, SP: Manole, 2010.
} 
pelos pacientes está a depressão, que normalmente aparece quando alguém é diagnosticado com uma doença crônica, como no caso das hepatites crônicas, e que pode ser acentuada com o uso da medicação.

Esses fatores e suas consequências interferem diretamente na rotina de vida da pessoa. Haja vista que alguns casos requerem cuidados por toda a vida. Assim, as pessoas com hepatites necessitam de muitas ações tanto por parte da sociedade (família, associações, instituições), como por parte do governo (instituições de saúde e instituições fiscalizadoras que venham a acompanhar as ações governamentais no que se refere à execução dos direitos das pessoas com hepatites).

\section{Da hepatite à advocacia}

Conforme o problema exposto anteriormente, se fez necessária a busca por melhorias no tratamento que era oferecido pelo estado. Essa busca foi caracterizada por intenso ativismo dos portadores de hepatite, bem como por seus familiares e simpatizantes da causa (alguns médicos). Entende-se essa atividade como o exercício da advocacia sanitária. Para uma melhor elucidação conceitual, faremos uma breve discussão do termo aqui adotado.

O termo advocacia sanitária vem sendo discutido recentemente pelos autores e estudiosos da área da saúde pública. Dallari ${ }^{11}$ afirma que a atividade de qualquer grupo de interesse visando influir na definição ou na implementação de uma política pública é qualificada de advocacy ou lobby, conforme o nível de renda tributável dessa organização. A mesma ainda define advocacia como um processo que utiliza um conjunto de estratégias políticas visando promover direitos não respeitados - seja por falta de regulamentação seja por falta de execução material da prestação prevista - através de meios legais e éticos, a favor de grupos sociais desfavorecidos ou oprimidos. Para tal, faz uso de instrumentos a fim de apurar o ambiente político e as razões técnicas em questão e, com isso, adequar a defesa às esferas de atuação necessária - sejam elas legislativa, administrativa, judiciária ou cultural -, construindo uma forte e embasada argumentação. Desde já se acredita que essa definição vai ao encontro da experiência que se pretende apresentar.

Delduque e Bardal ${ }^{12}$ afirmam que, quando se pensa em advocacia, imediatamente vem à mente a ideia daquele que detém um conhecimento técnico-forense que poderá ser posto a serviço de um interesse. No entanto, a advocacia pode ter um sentido mais amplo, significando a reivindicação de

\footnotetext{
${ }^{11}$ DALLARI, Sueli, Gandolfi. Advocacia em saúde no Brasil contemporâneo. Revista de Saúde Pública, São Paulo, v. 50, n. 6, 1996. Id. Direito sanitário: fundamentos, teoria e efetivação. In: ROCHA, Aristides Almeida; CESAR, Chester Luiz Galvão (Org.). Saúde Pública: bases conceituais. São Paulo: Atheneu, 2008.

${ }^{12}$ DELDUQUE, Maria Célia; BARDAL, Priscila Ariede Petinuci. Advocacia em saúde: prática cidadã para a garantia do direito à saúde - o caso do Projeto de Lei Complementar n. 01/2003. Revista de Direito Sanitário, São Paulo, v. 9, n. 1, p. 107-122, mar./jun. 2008.
} 
um direito ainda não reconhecido ou não materialmente garantido. Para isso, o advogado não precisa ser o bacharel legalmente habilitado, mas todo aquele que, comprometido com a causa a ser defendida, lançará mão de técnicas, processos e estratégias para atingir o pretendido. Reforçam ainda que advocacia em saúde constitui um processo de fortalecimento de cidadãos ou grupos de cidadãos para o exercício reivindicatório de seu direito à saúde, quando não usufruído plenamente, junto às instâncias estatais e não estatais, realizado por instrumento de persuasão e convencimento. Advogar em saúde significa reivindicar pelo direito à saúde de forma específica.

A advocacia, apesar de só recentemente ser discutida com mais propriedade e aprofundamento, vem sendo exercida por grupos diversos. Como resultado da advocacia em saúde, temos o próprio capítulo da saúde da Constituição de 1988. Esse movimento que resultou no reconhecimento da saúde como direito de todos também criou alguns mecanismos constitucionais que viabilizam e estimulam o exercício da advocacia em saúde.

Apesar de os direitos básicos estarem confirmados por normas legais, em alguns casos ocorrem falhas institucionais que limitam seu exercício, resultando em problemas que produzem danos individuais ou coletivos. No sentido aqui utilizado, a advocacia é dirigida a sanar esses problemas. Sua ação tem conotação política e se justifica quando há distribuição inadequada de autoridade ou de recursos ${ }^{13}$. Ainda nesse aspecto, conforme defendido por Dallari ${ }^{14}$, apesar do reconhecimento da saúde como direito confirmado pelo artigo $6^{\circ}$ da Constituição de 1988, ainda se faz necessário o direcionamento das ações de advocacia em saúde para a busca de sua efetivação. Desse modo, existem vários mecanismos capazes de viabilizar tal reivindicação junto ao poder legislativo, à administração pública e no judiciário.

Ainda conforme a autora, na prática, a advocacia é mais eficaz quando concentrada em assuntos específicos, não generalizados. Dessa forma, o problema deve ser bem identificado e caracterizado, para que, assim, se possa achar, mais eficazmente, uma solução apropriada.

É importante ressaltar que as ações da advocacia em saúde são realizadas de várias formas, por exemplo: através dos meios de comunicação e por grupos de pressão política, entre outros ${ }^{15}$. No caso em questão, a advocacia foi exercida por pressão de um grupo relativamente numeroso. E tal grupo se valeu de vários

\footnotetext{
${ }^{13}$ CANEL, Regina Célia; CASTRO, Cláudio Junqueira. A Advocacia em saúde como uma estratégia para a promoção da saúde. Revista de Direito Sanitário, São Paulo, v. 9, n. 1, p. 74-85, mar./jun. 2008.

${ }^{14}$ DALLARI, Sueli, Gandolfi. Advocacia em saúde no Brasil contemporâneo, cit. Id. Direito sanitário: fundamentos, teoria e efetivação, cit.

${ }^{15}$ CANEL, Regina Célia; CASTRO, Cláudio Junqueira. A Advocacia em saúde como uma estratégia para a promoção da saúde. Revista de Direito Sanitário, São Paulo, v. 9, n. 1, p. 74-85, mar./jun. 2008.
} 
mecanismos, desde a sensibilização popular em manifestações e panfletagens em via pública até ações judiciais, que serão descritas a seguir.

Zioni ${ }^{16}$ defende que as propostas de advocacia em saúde, juntamente com as de promoção em saúde, são exemplos de orientações que podem contribuir para a vivência democrática, pois informam e mobilizam a sociedade como um todo. "Trata-se de um conjunto de procedimentos que permitem uma divulgação de informações e uma mobilização, ou envolvimento de diferentes grupos sociais”. Assim, para que ocorra uma reflexão sobre a atividade democrática, é necessária uma discussão da participação política; entre tais atividades, incluem-se as de advocacia sanitária.

Delduque e Bardal $^{17}$ ressaltam que a síntese das cartas e declarações da Organização Mundial da Saúde (OMS) mostra que a saúde resulta de um conjunto de fatores individuais e coletivos (sociais, econômicos, políticos, étnicos, religiosos, culturais, psicológicos, do trabalho, biológicos, ambientais), interagindo em um processo dinâmico. As cartas consideram a saúde como um direito humano fundamental e essencial para o desenvolvimento pessoal, social e econômico. Sua manutenção deve ser o principal investimento social dos governos. Os documentos reforçam a ideia de que o processo saúde-doença não é apenas linear (resultante de causa-efeito), tampouco restrito ao ponto de vista biomédico, e sim deve ser percebido dentro de um novo modelo (holístico), no qual as metas da saúde são atingidas juntamente com a melhoria da qualidade de vida, a justiça social e o desenvolvimento sustentado. A participação comunitária é fundamental, e os profissionais de saúde devem assumir a tarefa de estimular e fortalecer a atuação da população nessas questões, instrumentalizando os cidadãos (indivíduos, grupos) para que seja exercido o direito à saúde.

Tudo isso constitui uma nova cultura, ou um novo paradigma, da saúde. Como mencionado acima, para que a participação popular seja de fato internalizada, se faz necessário - além da educação para a saúde e da informação - o direito de voz das pessoas e das comunidades, também chamado de empoderamento, no planejamento e na execução dos cuidados de saúde. O empoderamento significa aumento do poder e da autonomia pessoal e coletiva de indivíduos e grupos sociais interpessoais e institucionais. Ocorre em um contexto de mudança social e desenvolvimento político, que objetiva promover a equidade através de suporte mútuo, cooperação, autogestão e participação em movimentos sociais autônomos. O termo consagrou-se a partir da tradução da expressão inglesa

${ }^{16}$ ZIONI, Fabiola. Advocacia em saúde e sua contribuição para a democracia. Revista de Direito Sanitário, São Paulo, v. 9, n. 1 p. 70-73, mar./jun. 2008.

${ }^{17}$ DELDUQUE, Maria Célia; BARDAL, Priscila Ariede Petinuci. Advocacia em saúde: prática cidadã para a garantia do direito à saúde - o caso do Projeto de Lei Complementar n. 01/2003. Revista de Direito Sanitário, São Paulo, v. 9, n. 1, p. 107-122, mar./jun. 2008. 
empowerment, que preconiza, entre outros aspectos, o controle sobre os determinantes do processo-saúde por parte dos indivíduos e grupos. Em termos de sua origem no campo científico e nas políticas públicas, surge nas experiências de psicologia comunitária, de movimentos de autoajuda e de práticas sociais resultantes de reivindicações e lutas dos novos movimentos sociais, ocorridas nas décadas de 1960 a 80 em vários países ${ }^{18}$.

O empoderamento social tornou-se uma importante estratégia que pode contribuir para a consolidação de políticas de saúde. Além disso, colabora para a construção de políticas públicas sociais que têm como objeto a intervenção sobre os múltiplos fatores do processo saúde/doença, por exemplo: salário digno, moradia, saneamento e acesso a educação ${ }^{19}$. Como processo social, busca a transformação da realidade, incluindo condições e relações sociais, o que implica o envolvimento da população e de sujeitos organizados em rede. Ocorre em arenas conflitivas, em que se expressam relações de poder, as quais devem ser encaradas não como algo estanque e determinado, mas plástico, flexível e modificável pela ação-reflexão-ação humana, à medida que os indivíduos sintam-se capazes e motivados para intervir em sua realidade ${ }^{20}$.

Partindo-se desse pressuposto, acredita-se que foi na busca de empoderamento que esse grupo de portadores de hepatite se uniu - para tentar viabilizar melhores condições de tratamento nos serviços de saúde. Dessa forma, tendo como contexto essas arenas conflitivas, lançaram-se na disputa por poder, através dos mecanismos que tinham ao alcance.

\section{A associação}

Como visto, os portadores de hepatite sentiram a necessidade de se organizar para reivindicarem, junto às instituições, atenção a suas necessidades decorrentes da doença. Conforme exposto, o tratamento extremamente custoso das hepatites obrigou os portadores a terem posturas pró-ativas, para garantir não só o acesso ao tratamento, mas também possibilidade de sobrevivência, já que se tratava de doença fatal.

Assim, os portadores mais atuantes nas ações reivindicativas fundaram em 1993 a associação, a primeira organização não governamental (ONG) de portadores de hepatites do Brasil. Desse modo, veem-se, refletidas no ativismo

\footnotetext{
${ }^{18}$ KLEBA, Maria Elisabeth; WENDAUSEN, Agueda. Empoderamento: processo de fortalecimento dos sujeitos nos espaços de participação social e democratização política. Saúde e Sociedade, São Paulo, v. 18, n. 4, 2009.

${ }^{19}$ CARVALHO, Sérgio Resende; GASTALDO, Denise. Promoção à saúde e empoderamento: uma reflexão a partir das perspectivas crítico-social pós-estruturalista. Ciência e Saúde Coletiva, São Paulo, v. 2, n. 13, 2008.

${ }^{20} \mathrm{KLEBA}$, Maria Elisabeth; WENDAUSEN, Agueda. O processo de pesquisa como espaço e processo de empoderamento. Interface: comunicação saúde e educação, São Paulo, v. 14, n. 33, abr./jun. 2010.
} 
dessas pessoas, ações que proporcionam o empoderamento e a advocacia sanitária, conforme os apontamentos teóricos apresentados. Para Falcão ${ }^{21}$, as organizações não governamentais são uma forma de institucionalizar a mobilização, a organização e a participação dos cidadãos no bem comum. Portanto, pode-se afirmar que as atividades das organizações podem, ou não, contribuir para consolidar e expandir democracias. Atuar em uma organização é exercer cidadania. O autor ainda afirma:

(...) quanto mais plurais entidades da sociedade civil, fundações, ONGs ou associações comunitárias tivermos, capazes de mobilizar e organizar sobre formas diversas cidadãos os mais diversos possíveis, mais estaremos contribuindo para uma participação igualitária de todos na decisão pública. (p. 64).

Bochio e Fortes ${ }^{22}$ defendem que a participação social acontece por intermédio da ONG, enquanto ator social, em um misto de ação solidária e ativismo político. Os autores, ao discutirem em seu artigo a influência da AIDS no desenvolvimento organizacional das ONGs, argumentam que as mesmas surgiram como iniciativas emergenciais para responder a uma necessidade e, de maneira despretensiosa, foram se estruturando como organizações com propósitos de promoção social. Trata-se de um propósito ambicioso, visto que é mais do que introduzir um novo produto: é uma interferência cultural baseada em novos sentidos e valores.

Sobre a relevância das ONGs no atual formato político global, $\mathrm{Nader}^{23}$, ao discorrer sobre o papel das ONGs no Conselho de Direitos Humanos da Organização das Nações Unidas (ONU), afirma que, na extinta Comissão de Direitos Humanos da entidade, as ONGs tiveram papel ativo importante, e, que, no novo Conselho, a participação das mesmas continuará essencial, buscando aproximá-lo das realidades locais de violação de direitos humanos e monitorando os posicionamentos dos países que o compõem. Para a autora, o fortalecimento da participação das ONGs dos países em desenvolvimento torna-se necessário mais do nunca.

Vê-se, desse modo, que as ONGs têm tido um papel preponderante no atual cenário político mundial e se tornado um ator social indispensável para o exercício da democracia e cidadania. Portanto, a criação da Associação de Portadores de Hepatites do Acre (APHAC) foi essencial na luta travada pelos doentes para que o poder público lhes oferecesse possibilidades de sobrevivência.

\footnotetext{
${ }^{21}$ FALCÃO, Joaquim. Democracia, direito e terceiro setor. 2. ed. Rio de Janeiro: FGV, 2006.

${ }^{22} \mathrm{BOCHIO}$, leda Maria Siebra; FORTES, Paulo Antonio de Carvalho. A influência da AIDS no processo de desenvolvimento organizacional das organizações não-governamentais: um estudo de caso sobre a Casa de Assistência Filadélfia. Caderno de Saúde Pública, São Paulo, v. 11, n. 24, 2008.

${ }^{23}$ NADER, Lúcia. O papel das ONGs no Conselho de Direitos Humanos da ONU. SUR-Revista Internacional de Direitos Humanos, ano 4, n. 7, 2007.
} 
Segundo relato do ex-presidente da associação, toda essa trajetória iniciou-se nos primeiros anos da década de $1990^{24}$, com alguns poucos portadores de hepatites que, motivados por uma médica infectologista [que ao longo desses anos se mostrou muito ativa na causa], lutavam para comprar a medicação, fazendo pedágios nas ruas, rifas, apelos nas emissoras de rádio e televisão e, posteriormente, o apelo ao poder público.

Houve nesse período várias mobilizações, inclusive com ações na Justiça e com intervenção do Ministério Público, que forçaram o Estado a custear o tratamento. Muitos portadores foram a óbito nesse período, e o Acre foi obrigado a indenizar familiares de doentes crônicos. A maioria das intervenções movidas teve a interferência da associação ${ }^{25}$.

Finalmente, em 1998, o governo estadual incluiu a medicação do tratamento das hepatites na lista de medicamentos excepcionais que seriam comprados pelo poder público, conforme artigo publicado em um jornal de circulação local. Entretanto, em entrevista a esse mesmo jornal, o então presidente da associação complementou: "o que não significa que houve tratamento disponível"26.

Mesmo sendo obrigado a manter o tratamento medicamentoso, o Estado muitas vezes interrompia o fornecimento da medicação, apesar de o tratamento dever ser contínuo por no mínimo seis meses. Além disso, os portadores recém-diagnosticados tinham dificuldades para ser incluídos no rol para a compra da medicação. A fim de receber as medicações, muitas vezes os portadores da doença se utilizavam de alguns artifícios, como apelar para as relações de apadrinhamento. Desse modo, a distribuição dos medicamentos, além de insuficiente e falha, era também iníqua.

Devido ao processo de compra e distribuição da medicação não atender a todos que necessitavam de tratamento, conforme exposto, o próprio ex-presidente da associação conta que aguardou durante um ano para entrar na lista dos seletos portadores que recebiam o tratamento - apesar de seu estado clínico ser grave, ao ponto de ele ir para a fila de transplante hepático.

Alguns portadores de hepatites, quando não tinham seus direitos à distribuição de medicação validados, como nesse caso, acionavam o Ministério Público. Sua intervenção foi fundamental para legitimar esse direito, assegurado legalmente. Sobre a atuação da Justiça no âmbito da saúde, consta no documento do Ministério da Saúde acerca do papel dos órgãos jurídicos na saúde que a Constituição da República Federativa do Brasil, em consonância com a evolução constitucional contemporânea,

\footnotetext{
${ }^{24}$ Depoimento feito em entrevista concedida ao pesquisador em 30 de outubro de 2011.

${ }^{25}$ Segundo relato do atual presidente da associação, Heitor Andrade de Macedo Filho, em entrevista concedida ao pesquisador em 3 de novembro de 2011.

${ }^{26}$ Reportagem publicada no jornal diário do Estado do Acre, Pagina 20, dia 12 de agosto de 2013.
} 
incorporou em seu texto a saúde como bem jurídico e direito social, mas também como direito fundamental, outorgando-lhe uma proteção jurídica especial ${ }^{27}$.

Nesse aspecto, cabe enfatizar que a sociedade em geral, quando em situação de ausência do cumprimento do direito à saúde, pode lançar mão de um forte aliado - o Ministério Público -, visto que a Constituição de 1988 consagrou as ações e os serviços de saúde como de "relevância pública" e definiu entre as funções institucionais do Ministério Público a de zelar pelo efetivo respeito dos serviços de relevância pública aos direitos assegurados na Constituição, promovendo as medidas necessárias à sua garantia (artigo 129, inciso II). Como se trata de zelar pelo efetivo respeito aos direitos, a relevância se traduz pelo serviço prestado, quer dizer, a nota distintiva dessa relevância pública não é a titularidade de quem presta o ato ou serviço de saúde (se o Estado ou o setor privado), mas a essencialidade de sua prestação para o interesse social, cabendo ao Ministério Público o controle da efetiva prestação ${ }^{28}$.

Como exemplo da ação do Ministério Público como interventor para assegurar os direitos da pessoa portadora de hepatite, temos uma sentença do Tribunal de Justiça no ano de 2004, divulgada em jornal de circulação local ${ }^{29}$ :

(...) o pleno do Tribunal de Justiça (...) concedeu liminar pleiteada pelo Ministério Público Estadual, obrigando o estado do Acre, por meio da Secretaria Estadual de Saúde, a custear os exames de controle (PCR-DNA-HBV) dos cidadãos A.M.S., e J.M.S. Os dois são portadores crônicos da doença e por orientação da médica C.L. precisam realizar os exames que só são realizados na rede privada e custam em média $\mathrm{R} \$ 850,00$.

Conforme exposto nessa ação, além da medicação, havia também a problemática dos exames de acompanhamento. Segundo o relato do Secretário de Saúde da época ao mesmo jornal, os exames não eram (até então) custeados pelo SUS, o que justificava a recusa da Secretaria de Saúde em custear a realização dos mesmos. Para que tais exames passassem a ser pagos pelo poder público, foi necessário que a promotora da Promotoria Especializada de Defesa da Cidadania e Saúde Pública impetrasse mandado de segurança contra a Secretaria de Saúde. Essa decisão judicial em favor dos portadores de hepatite abriu precedente para outras reivindicações na Justiça.

Toda essa pressão social exercida pelos portadores da doença, por seus familiares e pela associação, envolvendo até mesmo os órgãos jurídicos, resultou

\footnotetext{
${ }^{27}$ MINISTÉRIO DA SAÚDE. Fundação Oswaldo Cruz. Questões atuais do direito sanitário. Brasília: Ed. do Ministério da Saúde, 2006. Disponível em: <http://www.estig.ipbeja.pt/ ac_direito/06_0860_M.pdf>. Acesso em: 30 mar. 2014.

${ }^{28}$ Id. Ibid.

${ }^{29}$ Reportagem publicada no Jornal “A tribuna”, ano XI, no .265/Rio Branco-Acre/sexta-feira, 25 de fevereiro de 2005.
} 
no projeto do então Senador Sebastião Viana, que, pelo fato de ser médico infectologista e pesquisador de hepatites, foi ativo na conquista do tratamento. Como relatado pelo Jornal do Mandato ${ }^{30}$ :

a Comissão de Assuntos Sociais aprovou, no dia 23 de outubro [2003], em caráter terminativo, o projeto de Autoria do Senador Tião Viana que estabelece obrigatoriedade de distribuição gratuita de medicamentos para doentes com hepatites crônicas, portadores do vírus de hepatite e pacientes com fibrose cística. O projeto segue para apreciação na Câmara dos Deputados e, se aprovado, a distribuição dos medicamentos será feita pelo Sistema Único de Saúde (SUS).

A seguir, tem-se a lista de algumas leis que configuram conquistas muito significativas das pessoas com hepatites crônicas. Apesar de a APHAC não estar relacionada diretamente com a criação ou a implementação das leis a seguir, as mesmas configuram ganhos a todos os portadores de hepatites, incluindo os do Acre.

- Assistência terapêutica integral e exames gratuitos: PL n. 2.092/2003; PL n. 3.706/2004; Mandado de Segurança n. 24.197 - PR (2007/0112500-5); e Lei Federal n. 11.255/2005.

Art. $1^{\circ} \mathrm{O}$ Sistema Único de Saúde - SUS prestará atenção integral à pessoa portadora de hepatite, tendo como diretrizes os princípios de universalidade, integralidade, equidade, descentralização e participação da sociedade na definição e no controle das ações e dos serviços que se fizerem necessários ${ }^{31}$.

- Auxílio-Doença ou aposentadoria por invalidez ou integral: Lei Federal n. 11.052/2004;

XIV - os proventos de aposentadoria ou reforma motivada por acidente em serviço e os percebidos pelos portadores de moléstia profissional, tuberculose ativa, alienação mental, esclerose múltipla, neoplasia maligna, cegueira, hanseníase, paralisia irreversível e incapacitante, cardiopatia grave, doença de Parkinson, espondiloartrose anquilosante, nefropatia grave, hepatopatia grave, estados avançados da doença de Paget (osteíte deformante), contaminação por radiação, síndrome da imunodeficiência adquirida, com base em conclusão da medicina especializada,

\footnotetext{
${ }^{30}$ Notícia Publicada no site do Senado, dia 23 de Outubro de 2003. Disponível em: <http://www.senado.gov. br/noticias/jornal/cidadania/hepatite/not003.htm>. Acesso em: 06 mar. 2015.

${ }^{31}$ BRASIL. Lei Federal n. 11.255, de 27 de dezembro de 2005. Define as diretrizes da Política de Prevenção e Atenção Integral à Saúde da Pessoa Portadora de Hepatite, em todas as suas formas, no âmbito do Sistema Único de Saúde - SUS, e dá outras providências. Disponível em: <http://www.planalto.gov.br/ ccivil_03/_Ato2004-2006/2005/Lei/L11255.htm>. Acesso em: 06 mar. 2015.
} 
mesmo que a doença tenha sido contraída depois da aposentadoria ou reforma ${ }^{32}$;

- e Portaria Interministerial n. 2.998/2001:

Art. $1^{\circ}$. As doenças ou afecções abaixo indicadas excluem a exigência de carência para a concessão de auxílio-doença ou de aposentadoria por invalidez aos segurados do Regime Geral de Previdência Social - RGPS: I - tuberculose ativa; II - hanseníase; III- alienação mental;(...)XIV - hepatopatia grave ${ }^{33}$.

- Isenção de impostos: Lei Federal n. 8.541/1992; Lei Federal n. 9.250/1995; Lei Federal n. 7.713/1988); e Lei Federal n. 11.052/2004:

Altera o inciso XIV da Lei n. 7.713, de 22 de dezembro de 1988, com a redação dada pela Lei no 8.541, de 23 de dezembro de 1992, para incluir entre os rendimentos isentos do imposto de renda os proventos percebidos pelos portadores de hepatopatia grave ${ }^{34}$.

- Cobertura total dos planos de saúde para diagnóstico e tratamento das hepatites: RDC n. 81; Resolução CFM n. 1.673/2003):

Art. 12. São facultadas a oferta, a contratação e a vigência dos produtos de que tratam (...) segundo as seguintes exigências mínimas: (Redação dada pela Medida Provisória n. 2.177-44, de 2001):

I - quando incluir atendimento ambulatorial: a) cobertura de consultas médicas, em número ilimitado, em clínicas básicas e especializadas, reconhecidas pelo Conselho Federal de Medicina; b) cobertura de serviços de apoio diagnóstico e tratamento e demais procedimentos ambulatoriais, solicitados pelo médico assistente;

\section{(..)}

II - (...); b) cobertura de serviços de apoio diagnóstico, tratamentos e demais procedimentos ambulatoriais, solicitados

\footnotetext{
${ }^{32}$ BRASIL. Lei Federal n. 11.052, de 29 de dezembro de 2004. Altera o inciso XIV da Lei no 7.713, de 22 de dezembro de 1988, com a redação dada pela Lei no 8.541, de 23 de dezembro de 1992, para incluir entre os rendimentos isentos do imposto de renda os proventos percebidos pelos portadores de hepatopatia grave. Disponível em: <http://www.planalto.gov.br/ccivil_03/_Ato2004-2006/2004/lei/L11052.htm>. Acesso em: 06 mar. 2015.

${ }^{33}$ BRASIL. Portaria Interministerial MPAS/MS n. 2.998, de 23 de agosto de 2001. Disponível em: <http:// www3.dataprev.gov.br/sislex/paginas/23/2011/..\%5C..\%5C65\%5CMPAS-MS\%5C2001\%5C2998.htm>. Acesso em: 06 mar. 2015.

${ }^{34}$ BRASIL. Lei Federal n. 11.052, de 29 de dezembro de 2004, cit.
} 
pelo médico assistente; (Redação dada pela Medida Provisória n. $2 \cdot 177-44$, de 2001$)^{35}$

Essa garantia, pela legislação, do tratamento gratuito fornecido integralmente pelo poder público foi, sem dúvida, a maior conquista dos portadores de hepatites - embora a Lei n. 11.255/2005 que obriga o SUS a custear o tratamento integral para hepatites crônicas tenha sido sancionada somente no ano de 2005. Nesse processo, não se pode negar a influência dos apelos dos portadores associados à APHAC ao então senador Tião Viana (PT/AC) - que, conforme citado anteriormente, se posicionou como ativista e defendeu a causa no Senado, apresentando o Projeto de Lei do Senado n. 85/2002, que estabelece obrigatoriedade de distribuição gratuita de medicamentos para doentes com hepatites crônicas, portadores do vírus de hepatite e pacientes com fibrose cística, e outros projetos de lei que têm como temática as hepatites (como o Projeto de Lei do Senado n. 474/1999, que propõe a instituição do dia nacional de vacina contra a hepatite B; e o Projeto de Lei do Senado n. 283/1999, que propõe a pesquisa obrigatória da hepatite B durante a assistência pré-natal e a vacinação dos recém-nascidos).

$\mathrm{O}$ ativismo da APHAC foi tão significativo, que, segundo relato da ex-coordenadora estadual de hepatites, a própria distribuição dos medicamentos aos portadores era feita inicialmente por intermédio da associação. A associação se fez ouvir nas discussões, reivindicando em fóruns, encontros locais e regionais (incluindo questões judiciais, como visto), até chegar ao projeto de lei, que resultou no tratamento que é oferecido hoje, com fornecimento totalmente gratuito de todas as medicações necessárias.

Além disso, o tratamento inclui a realização dos exames de monitoramento necessários ao tratamento e a implantação de uma estrutura de suporte, com serviços odontológicos, psicológicos e acompanhamento clínico em sistema de plantão disponível diariamente.

\section{A associação na atualidade}

A APHAC foi fundada em 7 de maio de 1993 e, como dito, foi a primeira ONG de portadores de hepatites do Brasil. A associação, hoje com 21 anos de funcionamento, tem 6.600 associados em todo o Acre. Sua sede fica na capital e tem cinco núcleos localizados nos municípios de Cruzeiro do Sul, Epitaciolândia, Tarauacá, Brasileia e Feijó ${ }^{36}$. Ao longo de todos esses anos, a associação vem somando várias conquistas em prol dos portadores de hepatites do estado. Conforme exposto

\footnotetext{
${ }^{35}$ BRASIL. Lei Federal n. 9.656, de 3 de junho de 1988. Dispõe sobre os planos e seguros privados de assistência à saúde. Disponível em: <http://www.planalto.gov.br/ccivil_03/leis/L9656compilado.htm>. Acesso em: 06 mar. 2015.

${ }^{36}$ Segundo informações concedidas pela secretária da APHAC.
} 
anteriormente, surgiu em decorrência da necessidade da advocacia dos portadores de hepatites que não tinham acesso ao tratamento gratuito, como preconizado na Constituição de 1988.

Além, é claro, das conquistas de melhorias na qualidade da assistência médica e farmacêutica, a associação conquistou como direito aos seus associados:

(a) passe gratuito de ônibus interestadual;

(b) descontos em empresas parceiras, drogarias, laboratórios;

(c) facilidade no acesso ao diagnóstico e tratamento da hepatite, através de parcerias com os serviços de referência do estado;

(d) fornecimento de cestas básicas com verduras e frutas, todas as terças-feiras, para os associados "mais carentes", através de um programa de compra que é feito em parceria com o governo do estado - na figura da Secretaria de Extensão Agroflorestal e Produção Familiar (Seaprof) e da Companhia Nacional de Abastecimento (Conab) e do programa SESC-Mesa Brasil, convênio assinado desde abril de 2009 ${ }^{37 ;}$

(e) assessoria jurídica (parceria com a OAB);

(f) aquisição junto ao Ministério da Saúde de equipamento laboratorial para a realização de exame de PCR-B (quantitativo/qualitativo) no laboratório de saúde pública do estado.

É importante ressaltar que esse equipamento foi doado pelo Ministério da Saúde para cinco estados, entre eles o Acre, devido à argumentação tanto de técnicos como de gestores e representantes da associação de portadores em fóruns e encontros nacionais ou regionais com representantes do Ministério da Saúde. De acordo com o relato tanto dos representantes governamentais como do representante da APHAC, a pressão exercida pela categoria foi fundamental para a conquista de aquisição do equipamento no Acre.

Além das atividades de assistência aos associados, a associação realiza também campanhas de diagnóstico das hepatites virais na comunidade em geral, em parceria com as secretarias de Saúde do estado e dos municípios. Devido à importância dessa associação para o apoio aos portadores, o próprio serviço de referência do estado em tratamento para as hepatites crônicas (Serviço de Atendimento Especializado) encaminha os recém-diagnosticados para a associação.

A APHAC teve sua atuação reconhecida inclusive pelo Ministério da Saúde, devido a um projeto apresentado por ela, juntamente com a associação Agá \& Vida (dos portadores de HIV do Acre), que foi contemplado com uma doação de R 65 mil

\footnotetext{
${ }^{37}$ Segundo informações obtidas da atual presidência da APHAC.
} 
da fundação patrocinada pelo multimilionário Bill Gates. O dinheiro foi empregado na compra de uma casa de apoio para pacientes em tratamento ${ }^{38}$.

\section{Considerações finais}

Para que a assistência integral ao portador de hepatite crônica no estado do Acre fosse realizada, se fez necessária a busca pela efetivação do direito à saúde, através de ações da advocacia sanitária em vários setores da sociedade - inclusive com o acionamento de órgãos de defesa de direitos como o Ministério Público. Essas ações foram imprescindíveis para validar um direito já garantido constitucionalmente. Este trabalho teve por objetivo mostrar a importância de pessoas com interesse comum (ou dificuldades comuns) se organizarem em busca de melhorias na qualidade de vida - sejam essas melhorias de cunho assistencial, como é o caso relatado, sejam de outra natureza - que estão garantidas constitucionalmente e que, na prática, precisam ser efetivadas. A Associação dos Portadores de Hepatite do Acre valeu-se de vários instrumentos para suas conquistas, mas estas só foram possíveis mediante a busca e a conscientização dos envolvidos de que tinham direitos - e de que esses direitos precisavam de reafirmação diante do poder público, que é o responsável por fazê-los valer. A conquista aqui enfatizada significou não só a garantia do direito à saúde, mas também do direito à vida, pois a ausência dessa assistência custou a vida de muitos. Mas se sabe que, em nosso país, ações como essas ainda são poucas, considerando-se a gama de dificuldades enfrentadas pelos cidadãos para a consolidação de direitos. Daí a relevância de fortalecer as entidades, com o intuito de proporcionar o empoderamento de grupos fragilizados, como nesse caso, por uma doença. Portanto, enfatiza-se neste trabalho que o envolvimento em entidades não governamentais pode ser um caminho para o exercício da cidadania.

\section{Referências}

BOCHIO, Ieda Maria Siebra; FORTES, Paulo Antonio de Carvalho. A influência da AIDS no processo de desenvolvimento organizacional das organizações não-governamentais: um estudo de caso sobre a Casa de Assistência Filadélfia. Caderno de Saúde Pública, São Paulo, v. 11, n. $24,2008$.

CANEL, Regina Célia; CASTRO, Cláudio Junqueira. A Advocacia em saúde como uma estratégia para a promoção da saúde. Revista de Direito Sanitário, São Paulo, v. 9, n. 1, p. 74-85, mar./jun. 2008.

CARVALHO, Sérgio Resende; GASTALDO, Denise. Promoção à saúde e empoderamento: uma reflexão a partir das perspectivas crítico-social pós-estruturalista. Ciência e Saúde Coletiva, São Paulo, v. 2, n. 13, 2008.

\footnotetext{
${ }^{38}$ Reportagem publicada no Jornal diário do estado do Acre “Página 20”, no dia 12 de Agosto de 2003
} 
DALLARI, Sueli, Gandolfi. Advocacia em saúde no Brasil contemporâneo. Revista de Saúde Pública, São Paulo, v. 50, n. 6, 1996.

DALLARI, Sueli, Gandolfi. Direito sanitário: fundamentos, teoria e efetivação. In: ROCHA, Aristides Almeida; CESAR, Chester Luiz Galvão (Org.). Saúde Pública: bases conceituais. São Paulo: Atheneu, 2008.

DATASUS. Banco de Dados do Sistema Único de Saúde. Indicadores e Dados Básicos - 2007. Indicadores demográficos/ Socioeconômicos, Brasília, 2007. Disponível em: <http://tabnet. datasus.gov.br/cgi/idb2007/matriz.htm\#socio >. Acesso em: 04 set. 2010.

DELDUQUE, Maria Célia; BARDAL, Priscila Ariede Petinuci. Advocacia em saúde: prática cidadã para a garantia do direito à saúde - o caso do Projeto de Lei Complementar n. 01/2003. Revista de Direito Sanitário, São Paulo, v. 9, n. 1, p. 107-122, mar./jun. 2008.

FALCÃO, Joaquim. Democracia, direito e terceiro setor. 2. ed. Rio de Janeiro: FGV, 2006.

ELIAS, Alexandre Nemer. Salud pública y derecho administrativo. Revista de Direito Sanitário, São Paulo, v. 9, n. 1, p. 206-208, mar./jun. 2008.

KLEBA, Maria Elisabeth; WENDAUSEN, Agueda. Empoderamento: processo de fortalecimento dos sujeitos nos espaços de participação social e democratização política. Saúde e Sociedade, São Paulo, v. 18, n. 4, 2009.

KLEBA, Maria Elisabeth; WENDAUSEN, Agueda. O processo de pesquisa como espaço e processo de empoderamento. Interface: comunicação saúde e educação, São Paulo, v. 14, n. 33, abr./jun. 2010.

MBHV. Movimento Brasileiro de Luta contra as Hepatites. Boletim Informativo, n. 1, set./nov. 2010.

MINISTÉRIO DA SAÚDE. Fundação Oswaldo Cruz. Questões atuais do direito sanitário. Brasília: Ed. do Ministério da Saúde, 2006. Disponível em: <http://www.estig.ipbeja.pt/ ac_ direito/06_0860_M.pdf>. Acesso em: 30 mar. 2014.

MINISTÉRIO DA SAÚDE. Secretaria de Vigilância em Saúde. Boletim Epidemiológico-Hepatites Virais, ano 3, n. 1, 2012. Disponível em: <http://www.aids.gov.br/sites/default/files/anexos/ publicacao/2012/51820/boletim_epidemiol_gico_hepatites_virais_2012_ve_12026.pdf >. Acesso em: 30 mar. 2014.

NADER, Lúcia. O papel das ONGs no Conselho de Direitos Humanos da ONU. SUR-Revista Internacional de Direitos Humanos, ano 4, n. 7, 2007.

PESSÔA, Isabela Nogueira. Aproximações acerca do cotidiano: enigmas e revelações de pessoas com hepatite B. São Paulo, 2009. 140p. [Dissertação].

SECRETARIA DE ESTADO DE SAÚDE DO ACRE. Assessoria. Agência de Notícias do Acre. Dia de Conscientização da Hepatite B no Acre. Rio Branco, 2007. 
SECRETARIA DE ESTADO DO PLANEJAMENTO. Acre em números: 2013. Rio Branco: Secretaria de Estado de Planejamento, 2013. Disponível em: <http://www.ac.gov.br/wps/ $\mathrm{wcm} /$ connect/e0c7fd0042426ebe9196b371c3a11451/Acre+Em+Nu\%CC\%81meros+2013+ web+editado.pdf?>. Acesso em: 30 mar. 2014.

SILVA, Rita do Socorro Uchôa et al. Avaliação da pré-triagem sorológica para o marcador do vírus da hepatite $\mathrm{B}$ (anti-HBc total) em candidatos à doação de sangue no Estado do Acre, 2002. Revista da Sociedade Brasileira de Medicina Tropical, v. 39, n. 2, p. 179-182, mar./abr. 2006.

VILLAS-BOAS, Sérgio. Murmurs from the silence: a report $\mathrm{n}$ hepatitis B and Delta in the Amazonia State of Acre, Brasil. Barueri, SP: Manole, 2010.

ZIONI, Fabiola. Advocacia em saúde e sua contribuição para a democracia. Revista de Direito Sanitário, São Paulo, v. 9, n. 1 p. 70-73, mar./jun. 2008.

Danúzia da Silva Rocha - Doutoranda pela Faculdade de Saúde Pública da Universidade de São Paulo. Docente do Centro de Ciências da Saúde e do Desporto da Universidade Federal do Acre. Rio Branco/AC, Brasil. E-mail: danuziarocha@yahoo.com.br.

Fabíola Zíoni - Professora Livre-Docente da Universidade de São Paulo. São Paulo/SP, Brasil. E-mail: fabiolaz@usp.br.

Ana Cássia Andrade Caetano - Assistente Social, especialista em Gestão em Políticas Sociais. Rio Branco/AC, Brasil. E-mail: anacassia-caetano@bol.com.br. 